\title{
Cardinal parameter meta-regression models describing Listeria monocytogenes growth in broth
}

\author{
Beatriz Nunes Silva ${ }^{\mathrm{a}, \mathrm{b}}$, Vasco Cadavez ${ }^{\mathrm{a}}$, José António Teixeira ${ }^{\mathrm{b}}$, Mariem Ellouze ${ }^{\mathrm{c}}$, \\ Ursula Gonzales-Barron ${ }^{\mathrm{a}, *}$ \\ ${ }^{a}$ Centro de Investigação de Montanha (CIMO), Instituto Politécnico de Bragança, Campus de Santa Apolónia, 5300-253 Bragança, Portugal \\ ${ }^{\mathrm{b}}$ CEB - Centre of Biological Engineering, University of Minho, Campus de Gualtar, 4710-057 Braga, Portugal \\ ${ }^{\mathrm{c}}$ Nestlé Research Centre, PO BOX44, CH-1000 Lausanne 26, Switzerland
}

\section{A R T I C L E IN F O}

\section{Keywords:}

Predictive microbiology

Meta-analysis

Secondary model

Kinetic parameters

Growth experiments

\begin{abstract}
A B S T R A C T
Since Listeria monocytogenes has a high case-fatality rate, substantial research has been devoted to estimate its growth rate under different conditions of temperature, $\mathrm{pH}$ and water activity $\left(\mathrm{a}_{\mathrm{w}}\right)$. In this study, published findings on L. monocytogenes growth in broth were extracted and unified by constructing meta-regression models based on cardinal models for (i) temperature (CM[T]), (ii) temperature and $\mathrm{pH}(\mathrm{CM}[\mathrm{T}][\mathrm{pH}])$, and (iii) temperature, $\mathrm{pH}$ and $\mathrm{a}_{\mathrm{w}}\left(\mathrm{CM}[\mathrm{T}][\mathrm{pH}]\left[\mathrm{a}_{\mathrm{w}}\right]\right)$. After assessing all the sources retrieved between 1988 until 2017, fortynine primary studies were considered appropriate for inclusion. Apart from the modelling variables, study characteristics such as: type of broth (BHI, TSB, TPB), reading method (colony-forming-units, CFU; or binarydilution optical density methods, OD), inoculum concentration and strain serotype, were also extracted. Metaregressions based on $\mathrm{CM}[\mathrm{T}]$ and $\mathrm{CM}[\mathrm{T}][\mathrm{pH}]$ were fitted on subsets of the 2009 growth rate measures and revealed that type of broth and reading method significantly modulated the cardinal parameter estimates. In the most parsimonious $\mathrm{CM}[\mathrm{T}][\mathrm{pH}]\left[\mathrm{a}_{\mathrm{w}}\right]$ meta-regression model, whereby the variability due to type of broth was extracted in a nested random-effects structure, the optimum growth rate $\mu_{\mathrm{opt}}$ of $L$. monocytogenes was found to be lower when measured as CFU (0.947 log CFU/h; SE $=0.094 \log \mathrm{CFU} / \mathrm{h})$ than when measured as OD (1.289 $\log$ $\mathrm{CFU} / \mathrm{h} ; \mathrm{SE}=0.092 \log \mathrm{CFU} / \mathrm{h})$. Such a model produced the following cardinal estimates: $T_{\min }=-1.273{ }^{\circ} \mathrm{C}$ $\left(\mathrm{SE}=0.179{ }^{\circ} \mathrm{C}\right), T_{\mathrm{opt}}=37.26{ }^{\circ} \mathrm{C}\left(\mathrm{SE}=0.688{ }^{\circ} \mathrm{C}\right), T_{\max }=45.12{ }^{\circ} \mathrm{C}\left(\mathrm{SE}=0.013{ }^{\circ} \mathrm{C}\right), p H_{\min }=4.303$ $(\mathrm{SE}=0.014), p H_{\mathrm{opt}}=7.085(\mathrm{SE}=0.080), p H_{\max }=9.483(\mathrm{SE}=0.080), a_{w \min }=0.894(\mathrm{SE}=0.002)$ and $a_{w}$ ${ }_{\mathrm{opt}}=0.995$ ( $\left.\mathrm{SE}=0.001\right)$. Integrating the outcomes from numerous $L$. monocytogenes growth experiments, this meta-analysis has estimated pooled cardinal parameters that can be used as reference values in quantitative risk assessment studies.
\end{abstract}

\section{Introduction}

Listeria monocytogenes is an infectious pathogen that has high ability to survive various environmental stresses and continue to grow at refrigeration temperatures during the shelf-life of some food product categories. The consumption of food contaminated with this bacterium can lead to listeriosis, an infection with high morbidity, hospitalisation, and mortality rates (Schlech \& Acheson, 2000). In 2018, in the European Union (EU), the case fatality was $15.6 \%$, making listeriosis one of the most serious foodborne illnesses under EU surveillance (EFSA \& ECDC, 2019). Moreover, among the cases with information on hospitalisation status, 97\% were hospitalised (EFSA \& ECDC, 2019).

Occurrence data in ready-to-eat (RTE) food samples has revealed that, in the EU, in 2017, L. monocytogenes occurrence was highest in fish and fishery products (6\%), RTE salads (4.2\%), RTE meat and meat products $(1.8 \%)$, soft and semi-soft cheeses $(0.9 \%)$, fruits and vegetables (0.6\%) and hard cheeses (0.1\%) (EFSA \& ECDC, 2018), while in 2018 , the occurrence of $L$. monocytogenes ranged from $0.09 \%$ for "hard cheeses made from pasteurised milk" up to $3.1 \%$ for RTE bovine meat (EFSA \& ECDC, 2019). Even though general, healthy population can be susceptible to listeriosis infection, the main groups of risk are people over 65 years-old, women aged 25-44 and children below 1 year of age (believed to be mainly pregnancy-related), and immunocompromised patients or patients with a higher number of severe comorbidities (EFSA BIOHAZ Panel, 2018).

Since one of the main goals and responsibilities of the food industry

\footnotetext{
* Corresponding author.

E-mail address: ubarron@ipb.pt (U. Gonzales-Barron).
} 
is to provide safe products to the consumers (Regulation (EU) No. 2073/2005), and considering the recently reported prevalence values and the occurrence of several outbreaks every year - fourteen in 2018 (EFSA \& ECDC, 2019), ten in 2017 (EFSA \& ECDC, 2018) - it can be suggested that the food industry would benefit from specific tools that can help perform safety assessments, and reduce the contamination of food products by L. monocytogenes. In this sense, predictive microbiology modelling is a tool that can be used to produce safe foods by evaluating if the control measures in place are able to prevent the proliferation of the pathogens to levels that might compromise consumers' health. The interest in this area has increased, and several models, based on the gamma concept proposed by Zwietering, Wijtzes, De Wit, and Riet (1992), have been devised to predict microbial behaviour considering extrinsic and intrinsic factors (such as temperature, pH, water activity, etc.): Lambert and Bidlas (2007), Baka, Van Derlinden, Boon, Mertens, and Van Impe (2013) and Nyhan, Begley, Mutel, Qu, Johnson, and Callanan (2018), to mention some. The gamma concept is based on the assumptions that: (i) the factors affecting microbial growth are independent and can be represented by a discrete term that is multiplied by other terms describing the effect of additional growth rate affecting factors; and (ii) each factor can be expressed as a fraction of the maximum growth rate, $\mu_{\max }$, and therefore each factor is normalised between 0 and 1 (Zwietering, Wijtzes, De Wit, \& Riet, 1992).

Introduced by Rosso, Lobry, Bajard, and Flandrois (1995), the cardinal parameter models (CPM) were developed according to the gamma concept, and have been widely used, as their advantage is the biological interpretation of the parameters (McKellar \& Lu, 2004), named cardinal values, which are linked to the minimum, optimal and maximum values that enable bacterial growth for each factor. The following equation displays a CPM that includes the effect of temperature (T), water activity $\left(\mathrm{a}_{\mathrm{w}}\right)$ and $\mathrm{pH}$, that modifies the optimum growth rate $\mu_{\mathrm{opt}}$,

$\mu_{\max }=\mu_{\text {opt }} \cdot C M_{2}(T) \cdot C M_{2}\left(a_{w}\right) \cdot C M_{1}(p H)$

$C M_{n}$ describes the relative effects of the factor $X$ on microbial growth rates (McKellar \& Lu, 2004), as follows,

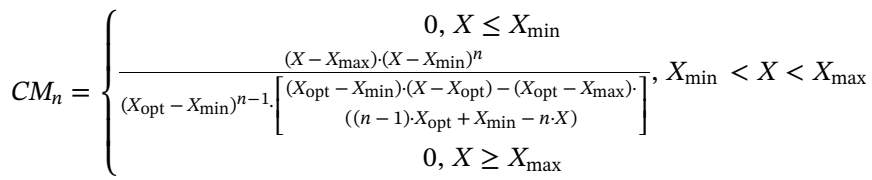

where $X_{\min }$ and $X_{\max }$ are, respectively, the values of $X_{i}$ below and above which no growth occurs; $X_{\mathrm{opt}}$ is the value at which bacterial growth is optimum (all terms are equal to 1 and therefore $\mu_{\max }=\mu_{\mathrm{opt}}$ ); and $n$ is a shape parameter ( $n=2$ for temperature and water activity; and $\mathrm{n}=1$ for $\mathrm{pH}$; according to Augustin and Carlier (2000a) and McKellar and Lu (2004).

Cardinal values to be used in further analysis and risk assessment simulations must be accurate and representative. In conventional cardinal values studies, cardinal parameters are determined independently. In this study, however, cardinal values are extracted at once by a meta-analysis of the outcomes from microbial growth experiments taken from the literature. In fact, meta-analysis is a powerful statistical tool that enables the integration and summarisation of results from distinct sources by assigning weighted values to each study's effect size (Xavier, Gonzales-Barron, Paula, Estevinho, \& Cadavez, 2014). In this sense, the objective of this study was to extract all published data on $L$. monocytogenes growth in broth and unify them in order to: (i) understand the variability in cardinal parameter estimates due to moderators such as broth type and reading method; and (ii) obtain representative and comprehensive cardinal parameters for temperature, $\mathrm{pH}$ and $\mathrm{a}_{\mathrm{w}}$ that can be useful as reference values. This was accomplished by constructing meta-regression models based on cardinal models for (i) temperature, (ii) temperature and $\mathrm{pH}$, and (iii) temperature, $\mathrm{pH}$ and $\mathrm{a}_{\mathrm{w}}$.

\section{Methodology}

Electronic, systematic literature search was carried out in Web of Science, PubMed and Scopus databases, as well as Google Scholar, to find suitable scientific articles, written in English, describing maximum growth rates of $L$. monocytogenes in broth. The search aimed to find quality studies validated by the scientific community.

The bibliographic searches were conducted by properly applying the AND and OR logical connectors to combine terms regarding $L$. monocytogenes growth, intrinsic/extrinsic factors, and growth models. The combination of keywords used in Web of Science, PubMed and Scopus databases were the following: (Listeria monocytogenes) AND (challenge OR fate OR inocul*) AND (growth) AND ("square-root" OR cardinal OR "secondary model" OR gamma) AND (minimum OR maximum OR optimal OR "growth rate" OR MIC OR isotherm* OR temperature OR storage OR pH OR "water activity" OR "organic acid"). In Google Scholar the keywords used were: (Listeria monocytogenes) AND ( $\mathrm{pH}$ OR temperature OR water activity OR organic acid) AND (growth).

When studies referenced in the collected articles were not present in the results of the literature search, said references were added. In addition, growth experiments data from ComBase and Nestle Challenge Test Database were also included. From these two sources, growth rate data from several organisations and/or companies were obtained. Other meta-analysis studies and systematic reviews were excluded, to avoid data duplication. The criteria for inclusion of data were: minimum of 4 data points (preferentially in the exponential phase); only experiments performed under aerobic conditions (or modified atmosphere where $\mathrm{O}_{2}$ is estimated to be around 16-20\%); absence of antimicrobial substances (essential oil and plant extracts, for instance), nitrates, or any other additive, and no treatments (such as irradiation); absence of competitive bacteria (no studies where several bacteria were inoculated simultaneously); dataset where $t_{0}$ (first sampling) is less than or equal to $10 \mathrm{~h}$; growth data reported as $\mathrm{OD} / \mathrm{h}$ included only if a calibration curve was provided to allow transformation to $\log \mathrm{CFU} / \mathrm{h}$; and growth rates obtained at temperature greater than or equal to $-2{ }^{\circ} \mathrm{C}$.

In order to obtain precise estimates of the cardinal parameters and reflect the quality of research design, specific weights were assigned to each primary study $(j)$ as a proportion between the number of time points (n) sampled along the experiment to calculate the growth rate, and the maximum number of times points sampled described in the database $(n=45)$. When a source did not present the number of time points sampled to calculate the growth rate, the lowest weight value from the data set (i.e., $n=4$ ) was assigned. Furthermore, for a primary study to be included in the meta-analysis, it had to report growth rate estimates from at least three different environmental conditions, or alternatively, to provide the data from at least three growth experiments so that the growth rate estimates could be computed thereof. This requisite was established to reduce imbalance in data structure, and to extract more accurately the random effects since their subject of variation is primarily the study in all meta-regressions.

Thus, after assessing all the information from the 279 recovered publications, forty-nine primary studies (see Supplementary File 1) published from 1988 until 2017 were considered appropriate for inclusion: they were comprised of forty published scientific articles; one unpublished article; and data from eight organisations/companies that had no reference regarding the year of data collection. From each of the forty-nine primary studies, the following data were extracted: maximum growth rate, standard error of the growth rate, temperature $\left({ }^{\circ} \mathrm{C}\right)$, $\mathrm{pH}, \mathrm{a}_{\mathrm{w}}$, type of broth (brain heart infusion [BHI], tryptic soy broth [TSB], tryptose phosphate broth [TPB] or undefined [UND]), reading method (colony-forming-units [CFU] or binary-dilution optical density methods [OD]), inoculum concentration ( $\log \mathrm{CFU} / \mathrm{g}$ or $\mathrm{CFU} / \mathrm{mL}$ ), strain serotype, number of time points for the growth experiment, and primary model used for growth rate determination. Growth data reported 
as $\mathrm{OD} / \mathrm{h}$ was not included if a calibration curve was not provided. In cases where growth rate was not directly reported in the study, it was computed from the growth data by fitting the Baranyi and Roberts model (Baranyi \& Roberts, 1994) using the Online DMFit tool from ComBase web interface. All the maximum growth rates $\left(\mu_{\max }\right)$, retrieved or calculated, were standardised to $\log$ base $10 \mathrm{CFU} / \mathrm{h}$, to make sure that when fitting the cardinal models on this response variable, the optimum growth rate $\left(\mu_{\text {opt }}\right)$ could be also obtained in this intuitive unit.

\subsection{Fitting exploratory meta-regressions based on CM[temperature] and CM[temperature $[\mathrm{pH}]$}

Overall, the meta-analytical dataset comprised 2009 growth rate measures. Before fitting the overarching meta-regression based on the full CPM (CM[temperature] $\left.[\mathrm{pH}]\left[\mathrm{a}_{\mathrm{w}}\right]\right)$ to the full data set, two simpler models were adjusted, with the purpose of conducting exploratory analysis: the CPM for temperature (CM[temperature]) and the CPM for temperature and $\mathrm{pH}(\mathrm{CM}[$ temperature $[\mathrm{pH}])$. The $\mathrm{CM}[$ temperature] model

$\sqrt{\mu_{\max }}=\sqrt{\mu_{\mathrm{opt}} \cdot C M_{2}(T)}$

was built to estimate the cardinal values for temperature, restricting the meta-analytical data to the optimal conditions of $\mathrm{pH}(6.5 \leq \mathrm{pH} \leq 8)$ and of $a_{w}\left(a_{w} \geq 0.95\right)$. The hypothesis about the "optimal conditions" of $\mathrm{pH}$ and $\mathrm{a}_{\mathrm{w}}$ is that some sets of conditions, as the ones defined, are closer to optimal growth than others. The optimal range of $\mathrm{pH}$ was defined with such values as the meta-analytical $\mathrm{CM}$ [temperature] $[\mathrm{pH}]$ model showed that the variation in $\mathrm{pH}$ from 6.5 to 7.5 did not cause large variability in $\mu_{\max }$ (see Supplementary File 2, Figure S2). Selecting optimal conditions of the factors that are not explanatory variables in the meta-regression model reduced the data set from 2009 to 1185 entries, and it was done to obtain representative and meaningful kinetic parameters. The CM[temperature] model (Eq. (3)) was fitted placing uncorrelated random effects due to primary study on the parameters $T_{\min } \mu_{\mathrm{opt}}$ and $T_{\mathrm{opt}}$, assuming that these follow normal distributions with mean zero and standard deviations $s_{\mathrm{u}}, \mathrm{s}_{\mathrm{v}}$ and $\mathrm{s}_{\mathrm{w}}$, respectively.

The second model built, CM[temperature] [pH],

$\sqrt{\mu_{\max }}=\sqrt{\mu_{\mathrm{opt}} \cdot C M_{2}(T) \cdot C M_{1}(p H)}$

included terms for temperature and $\mathrm{pH}$, allowing the estimation of cardinal values for both factors. This model was adjusted to growth rates obtained at optimal conditions of $\mathrm{a}_{\mathrm{w}}\left(\mathrm{a}_{\mathrm{w}} \geq 0.95\right)$; this is, using a data subset consisting of 1880 entries. In the $\mathrm{CM}$ [temperature][pH] model, the non-correlated random effects with primary study as subject of variation were placed on the parameters $\mu_{\mathrm{opt}}, T_{\mathrm{opt}}$ and $\mathrm{pH}_{\mathrm{opt}}$, assuming that these follow normal distributions with mean zero and and standard deviations $s_{u}, s_{v}$ and $s_{w}$, respectively.

Models from Eqs. (3) and (4) will be referred to as null models since they do not accommodate any study characteristics, also called moderators or descriptors. Moderators are variables that can be selected to be studied in depth according to the topic under investigation (Xavier, Gonzales-Barron, Paula, Estevinho, \& Cadavez, 2014). From each null model, the between-study variance $\tau^{2}$ was obtained.

The purpose behind increasing the complexity of the null models presented in Eqs. (3) and (4) was to ascertain the proportion of between-study variability in the optimum growth and cardinal parameters that could be explained by the most important moderators (Borenstein, Hedges, Higgins, \& Rothstein, 2009). Table 1 compiles the study characteristics extracted from the primary studies as well as the distribution of growth rate data among their categories. Nonetheless, not all of them could be evaluated in the meta-regressions. The effects of moderators such as strain serotype and primary model on the model parameters could not be tested due to the uneven distribution of the data. On the other hand, the effect of inoculum level was not studied because this variable and reading method were highly confounded,
Table 1

Number of growth rates per level of moderator available in the constructed database.

\begin{tabular}{cl}
\hline Moderator & $\begin{array}{l}\text { Data available for each moderator's } \\
\text { level }\end{array}$ \\
\hline Reading method & CFU: 1232 \\
& OD: 777 \\
\hline Strain serotype & $1 / 2 \mathrm{a}: 154$ \\
& $1 / 2 \mathrm{~b}: 89$ \\
& $1 / 2 \mathrm{c}: 56$ \\
& 4 ab: 80 \\
& $4 \mathrm{~b}: 1089$ \\
& Undefined: 541 \\
\hline Medium subcategory & TSB: 529 \\
& TPB: 283 \\
& BHI: 530 \\
& Undefined: 667 \\
\hline Inoculum level (log CFU/g or CFU/mL) & {$[2,3[: 15$} \\
& {$[3,4[: 88$} \\
& {$[4,5[: 30$} \\
& {$[5,6.5]: 300$} \\
\hline Primary model & Baranyi: 133 \\
& Gompertz: 4 \\
& Unstated: 1872 \\
\hline &
\end{tabular}

meaning that all growth rates originating from binary-dilution OD reading methods presented inoculum levels higher than $4 \log \mathrm{CFU} / \mathrm{g}$ (or/ml), whereas growth rates from CFU reading methods showed the majority of inoculum levels between 2 and $3 \mathrm{log} \mathrm{CFU} / \mathrm{g}$ (or/ml). Moreover, information regarding inoculum concentration was available for only $\sim 20 \%$ of the entries. Thus, heterogeneity analysis could only be carried out for three moderators: type of broth, reading method and inoculum level.

The influence of a moderator was tested by setting it to affect each of the model parameters in separate mixed-effects regressions. For instance, to assess the effect of broth type as a moderator in the $\mathrm{CM}$ [temperature] model, four separate mixed-effects models had to be adjusted since such a model is defined by four parameters. Thus, the separate mixed-effects models would test broth type as a predictor of $\mu_{\mathrm{opt}}$, as a predictor of $T_{\mathrm{min}}$, as a predictor of $T_{\mathrm{opt}}$ and as a predictor of $T_{\max }$. These models will be referred to as models with moderator.

The influence of moderators was tested by introducing them one by one in the null model. Type of broth and reading method were tested as moderators, thereby producing a total of 8 separate models with moderator when using $\mathrm{CM}$ [temperature] as the basis equation (2 moderators by 4 parameters), and 14 models with moderator when using CM[temperature] $[\mathrm{pH}]$ as the basis equation ( 2 moderators by 7 parameters). For every model with moderator, the proportion $\mathrm{R}^{2}$ of between-study variance explained by the moderator was calculated by comparing the residual between-study variance of the model with moderator $\left(\tau_{\text {res }}^{2}\right)$ with that of the null model $\left(\tau^{2}\right)$ (Gonzales-Barron \& Butler, 2011).

\subsection{Fitting the final CM[temperature $][\mathrm{pH}]\left[\mathrm{a}_{w}\right]$ meta-regression model}

The overarching or final meta-regression model was based on the $\mathrm{CM}[$ temperature $][\mathrm{pH}]\left[\mathrm{a}_{\mathrm{w}}\right]$ equation,

$\sqrt{\mu_{\max }}=\sqrt{\mu_{\mathrm{opt}} \cdot C M_{2}(T) \cdot C M_{1}(p H) \cdot C M_{2}\left(a_{w}\right)}$

and contained terms for temperature, $\mathrm{pH}$ and $\mathrm{a}_{\mathrm{w}}$, in order to allow for the determination of cardinal values for all three factors. This model was adjusted to the full meta-analytical data set $(\mathrm{N}=2009)$ since now there was no restriction imposed to the values of temperature, $\mathrm{pH}$ or $\mathrm{a}_{\mathrm{w}}$.

The most parsimonious CPM-based meta-regression model fitted to 
Table 2

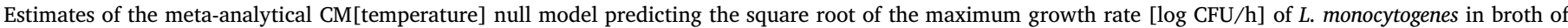

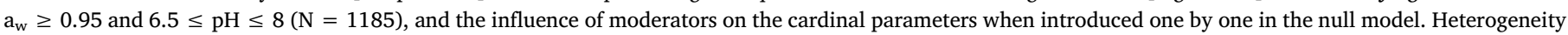
analysis comprises between-study variance $\left(\tau^{2}\right)$, residual between-study variance $\left(\tau_{\text {res }}^{2}\right)$ and explained between-study variance $\left(R^{2}\right)$.

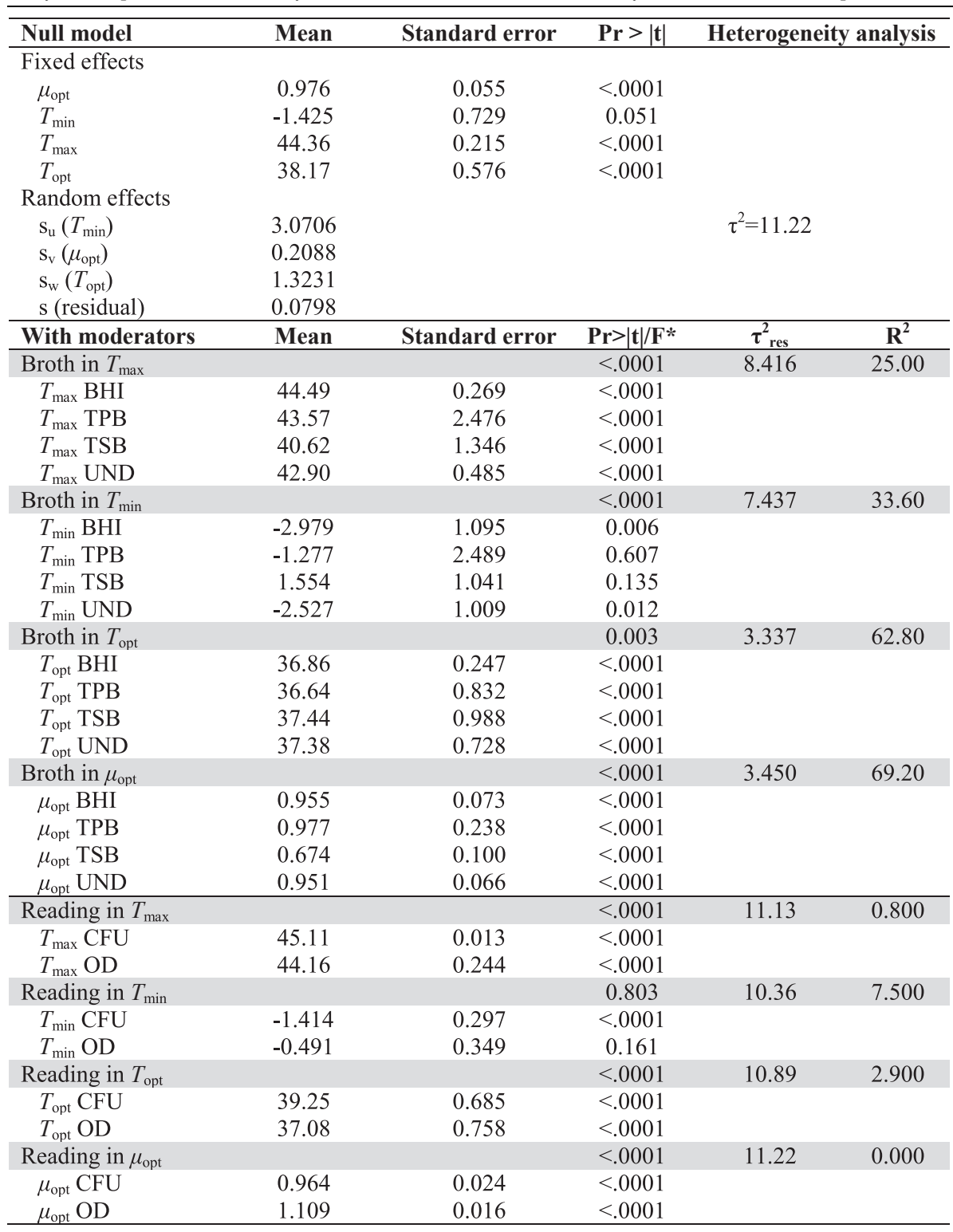

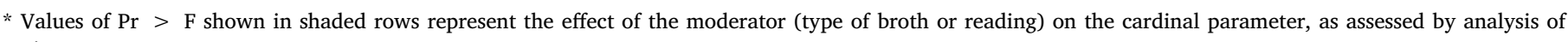
variance.

the data was of the form,

$\sqrt{\mu_{\max \mathrm{rm}(\mathrm{j})}}=\sqrt{\mu_{\mathrm{optrm}(\mathrm{j})}} \times$

$\sqrt{\frac{\left(T-T_{\max }\right) \cdot\left(T-T_{\min }\right)^{2}}{\left(T_{\mathrm{optm}(\mathrm{j})}-T_{\min }\right) \cdot\left[\left(T_{\mathrm{optm}(\mathrm{j})}-T_{\min }\right) \cdot\left(T-T_{\mathrm{optm}(\mathrm{j})}\right)\right.}} \times$

$\sqrt{\frac{\left(p H-p H_{\max }\right) \cdot\left(p H-p H_{\min }\right)}{\left[\left(p H_{\mathrm{optm}(\mathrm{j})}-p H_{\min }\right) \cdot\left(p H-p H_{\mathrm{optm}(\mathrm{j})}\right)\right.}} \times$

$\left.1-\left(p H_{\text {optm }(\mathrm{j})}-p H_{\max }\right)\left(p H_{\min }-p H\right)\right]$

$$
\begin{aligned}
& \sqrt{\frac{(a w-1.00) \cdot\left(a w-a w_{\min }\right)^{2}}{\left(a w_{\mathrm{optm}(\mathrm{j})}-a w_{\min }\right) \cdot\left[\left(a w_{\mathrm{optm}(\mathrm{j})}-a w_{\min }\right) \cdot\left(a w-a w_{\mathrm{optm}(\mathrm{j})}\right)\right.}}+\varepsilon_{r m(j)} \\
& \left.1-\left(a w_{\mathrm{optm}(\mathrm{j})}-1.00\right)\left(a w_{\mathrm{optm}(\mathrm{j})}+a w_{\min }-2 a w\right)\right] \\
& \mu_{\mathrm{optrm}(\mathrm{j})}=\mu_{\mathrm{optr}}+u_{m(j)}=\left(\beta_{0}+\beta_{1} \text { Reading }\right)+\left(u_{m}+u_{m(j)}\right) \\
& T_{\mathrm{optm}(\mathrm{j})}=T_{\mathrm{opt}}+\left(v_{m}+v_{m(j)}\right) \\
& p H_{\mathrm{optm}(\mathrm{j})}=p H_{\mathrm{opt}}+\left(w_{m}+w_{m(j)}\right) \\
& a w_{\mathrm{optm}(\mathrm{j})}=a w_{\mathrm{opt}}+\left(z_{m}+z_{m(j)}\right)
\end{aligned}
$$

where $\mu_{\mathrm{opt} \text { rm(j) }}, T_{\mathrm{opt} \mathrm{m}(\mathrm{j})}, p H_{\mathrm{opt} \mathrm{m}(\mathrm{j})}$ and $a w_{\mathrm{opt} \mathrm{m}(\mathrm{j})}$ were allowed to take in the random shifts $u_{m}+u_{m(j)}, v_{m}+v_{m(j)}, w_{m}+w_{m(j)}$ and $z_{m}+z_{m(j)}$, respectively, as realisations of the primary study $j$ nested in broth type $m$; while, in addition, the type of reading $r$ was presumed to modulate 


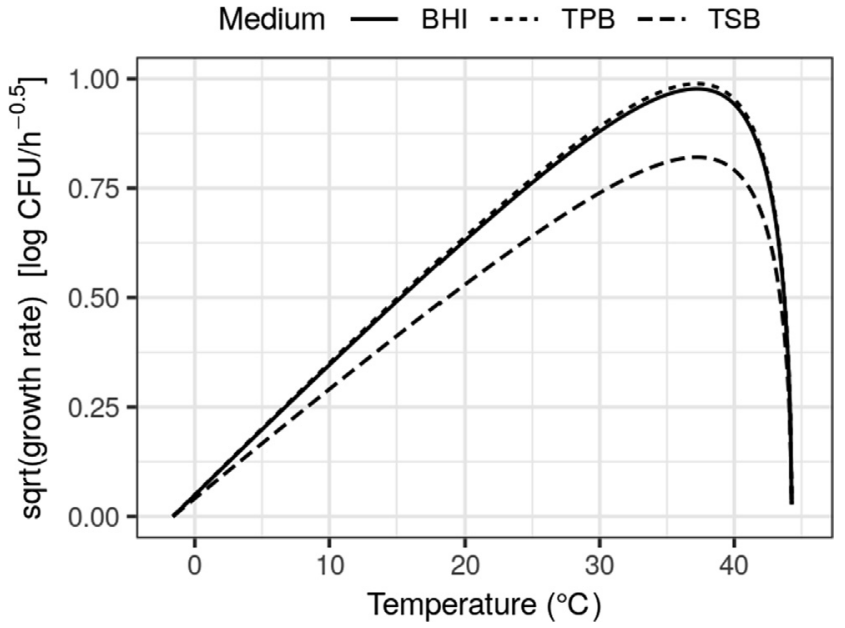

Fig. 1. Overall influence of type of broth as moderator affecting the optimum growth rate on the CM[temperature] meta-analytical model of $L$. monocytogenes in broth of optimum $\mathrm{a}_{\mathrm{w}}(\geq 0.95)$ and $\mathrm{pH}(6.5 \leq \mathrm{pH} \leq 8)$.

$\mu_{\text {opt rm(j) }}$ as a fixed effect. The random effects $u_{m}, v_{m}, w_{m}$ and $z_{m}$ were assumed to distribute independently as normal distributions with mean zero and standard deviations $s_{u m}, s_{v m}, s_{w m}$ and $s_{z m}$, respectively. Likewise, the random effects $u_{m(j)}, v_{m(j)}, w_{m(j)}$ and $z_{m(j)}$ were assumed to follow normal distributions with mean zero and standard deviations $\mathrm{s}_{u}$ $m(j), s_{v m(j)}, s_{w m(j)}$ and $s_{z m(j)}$, respectively. The residuals $\varepsilon_{r m(j)}$ followed a normal distribution with mean zero and standard deviation $s$. The

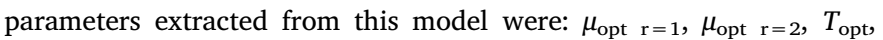
$p H_{\text {opt },} a_{w o p t}, T_{\min }, p H_{\min }, a_{w \min ,} T_{\max }$ and $p H_{\max }$. Nested random effects were fitted as uncorrelated, because the models tested with correlated random effects structure did not improve the fitting quality. As with the simpler CM[temperature] and CM[temperature][pH] models, the CM [temperature] $[\mathrm{pH}]\left[\mathrm{a}_{\mathrm{w}}\right]$ equation was fitted in its null form (without moderators) in order to extract $\tau^{2}$ to perform heterogeneity analysis. The proportion $\mathrm{R}^{2}$ of between-study variance explained by the moderators was calculated after fitting the full model of Eq. (6).

All the meta-regression models were fitted as weighted nonlinear mixed-effects models using the nlme function from the nlme package (v3.1-142; Pinheiro et al., 2019) implemented in R Studio version 1.0.136 ( $\mathrm{R}$ Core Team, 2019). Model parameters, as affected by moderators, were calculated from the fitted meta-regressions, and the significance of moderators was evaluated by analysis of variance $(\alpha=0.05)$.

\section{Results and discussion}

\subsection{CM[temperature] meta-regression model}

The results of the first meta-regression model, CM[temperature], are presented in Table 2. Analysing the $\tau_{\text {res }}^{2}$ values of the models with moderators (for example, $\tau_{\text {res }}^{2}=3.450$ for broth type in $\mu_{\text {opt }}$ ), a decrease can be observed when comparing to the $\tau^{2}$ values of the null model $\left(\tau^{2}=11.22\right)$. This means the moderator is responsible for some of the observed between-study heterogeneity, even if there is some remaining unexplained variability. This can also be seen by the $\mathrm{R}^{2}$ value, where for example the broth type explains $25 \%$ of the variability in $T_{\max }$ estimates, but there is still $75 \%$ of heterogeneity that cannot be accounted for by this moderator alone.

The present meta-regression showed that the reading method was a source of between-study variability to some extent $\left(R^{2}=0.8-7.5 \%\right)$, however not as important as the type of broth, which was responsible for $25-70 \%$ of the heterogeneity. The highest $\mathrm{R}^{2}$ was obtained when the broth type was set to affect the optimum growth rate. Fig. 1, constructed with basis on this model, depicts the influence of type of broth
(BHI, TPB and TSB) on the maximum growth rate; the UND (undefined) category was not displayed as it represents a collection of unnamed broths for comparison purposes only. TSB shows a particular impact on the maximum growth rate when compared to the other two broths, BHI and TPB. In fact, from Table 2, it is noticeable that all cardinal parameters estimates from TSB revealed fairly different means in comparison to estimates for BHI, TPB and UND growth rates: $T_{\max }$ and $\mu_{\mathrm{opt}}$ were clearly lower, while $T_{\min }$ and $T_{\text {opt }}$ were higher. For additional insight, a plot of the growth rates of $L$. monocytogenes retrieved from literature in distinct types of broth (BHI, TPB and TSB) of optimum $\mathrm{a}_{\mathrm{w}}$ $(\geq 0.95)$ and $\mathrm{pH}(6.5 \leq \mathrm{pH} \leq 8)$ as a function of temperature is available in the Supplementary File 2 (Fig. S1).

From the meta-analytical data set, the effect of inoculum level on the estimated cardinal parameters could not be elucidated because the variables inoculum level and reading method were highly confounded, as previously referred. Although available literature suggests that the inoculum concentration has no effect on the cardinal parameters determined (Gnanou Besse et al., 2006), this hypothesis may be difficult to confirm through meta-analysis, since, generally, higher inoculum levels are associated with optical density reading methods, while lower inoculum concentrations are commonly used when CFU reading methods are chosen, as our meta-analysis study reveals.

In terms of standard errors (SE), cardinal values estimated from TPB broth growth rates revealed generally higher values than standard errors of cardinal values from other media. The only exception was the SE of $T_{\text {opt }}$ from TSB (0.988), that was higher than the SE of the same cardinal value from TPB (0.832). Overall, it is likely that the increased standard errors in cardinal values estimated from TPB broth were caused by the lower amount of growth rate data originating from this medium $(\mathrm{N}=283)$, when compared to data from $\mathrm{BHI}(\mathrm{N}=530)$ or TSB $(\mathrm{N}=529)$ broths.

The mixed-effects models incorporating reading method as a moderator revealed significant differences between CFU and OD methodologies when estimating $T_{\text {max }}, T_{\text {opt }}$ and $\mu_{\text {opt }}$. On the other hand, $T_{\text {min }}$ estimates did not appear to be statistically different when using CFU or OD reading methods $(\mathrm{p}=0.803)$.

\subsection{CM[temperature] $[\mathrm{pH}]$ meta-regression model}

Considering the outcomes of the first meta-regression model, specifically that reading method and broth type should be included as moderators to account for the existing variability between growth rates extracted from literature, the $\mathrm{CM}[$ temperature] $[\mathrm{pH}]$ meta-regression was built, and the results are shown in Table 3. In this model, the variances of the random effects were significant only for $\mu_{\mathrm{opt}}, T_{\mathrm{opt}}$ and $p H_{\text {opt }}$. Thus, the random effects for the other parameters $\left(T_{\min }, p H_{\min }\right.$, $T_{\max }$ and $\left.p H_{\max }\right)$ were dropped from the model and are not presented in Table 3.

The main noticeable difference is the large reduction in heterogeneity. In the $\mathrm{CM}$ [temperature], the data was taken from broth of a wide range of $\mathrm{pH}(6.5 \leq \mathrm{pH} \leq 8)$, whose value was not accounted for in the model. In the CM[temperature] $[\mathrm{pH}]$ model, the between-study variance $\left(\tau^{2}=3.949\right)$ and the residual between-study variance $\left(\tau_{\text {res }}^{2}\right)$ both decreased considerably, which means that including the $\mathrm{pH}$ term was a substantial contribution to reducing the variability previously observed in the $\mathrm{CM}$ [temperature] meta-regression. If the $\mathrm{pH}$ range defining "optimal conditions" had been restricted for the CM[temperature] analysis, the number of observations of the data set would have decreased, and very likely the $\tau^{2}$ (between-study heterogeneity in growth rate) of the null model would have been even smaller. Nonetheless, the selection of the $\mathrm{pH}$ interval only aimed at conducting an exploratory analysis of the data to assess the relative importance of the moderating variables in explaining the between-study variability in growth rate.

In this second model, the type of broth was, once again, able to explain a large percentage of the heterogeneity between studies 
Table 3

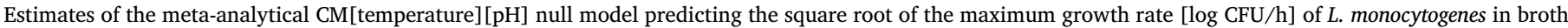

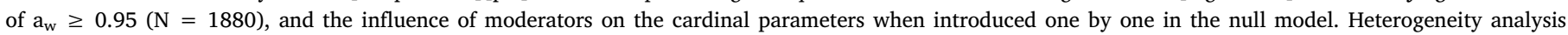
comprises between-study variance $\left(\tau^{2}\right)$, residual between-study variance $\left(\tau_{\text {res }}^{2}\right)$ and explained between-study variance $\left(R^{2}\right)$.

\begin{tabular}{|c|c|c|c|c|c|}
\hline \multirow{2}{*}{$\begin{array}{l}\text { Null model } \\
\text { Fixed effects }\end{array}$} & \multirow[t]{2}{*}{ Mean } & \multirow[t]{2}{*}{ Standard error } & \multirow[t]{2}{*}{$\operatorname{Pr}>|\mathbf{t}|$} & \multicolumn{2}{|c|}{ Heterogeneity analysis } \\
\hline & & & & & \\
\hline$\mu_{\mathrm{opt}}$ & 0.953 & 0.058 & $<.0001$ & & \\
\hline$T_{\min }$ & -1.073 & 0.208 & $<.0001$ & & \\
\hline$T_{\max }$ & 45.11 & 0.011 & $<.0001$ & & \\
\hline$T_{\mathrm{opt}}$ & 37.91 & 0.601 & $<.0001$ & & \\
\hline$p H_{\min }$ & 4.295 & 0.010 & $<.0001$ & & \\
\hline$p H_{\max }$ & 9.451 & 0.138 & $<.0001$ & & \\
\hline$p H_{\mathrm{opt}}$ & 7.062 & 0.120 & $<.0001$ & & \\
\hline \multicolumn{6}{|l|}{ Random effects } \\
\hline $\mathrm{s}_{\mathrm{u}}\left(\mu_{\mathrm{opt}}\right)$ & 0.297 & & & $\tau^{2}=3.949$ & \\
\hline $\mathrm{s}_{\mathrm{v}}\left(T_{\mathrm{opt}}\right)$ & 1.930 & & & & \\
\hline $\mathrm{s}_{\mathrm{w}}\left(p H_{\mathrm{opt}}\right)$ & 0.369 & & & & \\
\hline $\mathrm{s}$ (residual) & 0.081 & & & & \\
\hline With moderators & Mean & Standard error & $\operatorname{Pr}>|t| / \mathbf{F}^{*}$ & $\tau_{\text {res }}^{2}$ & $\mathbf{R}^{2}$ \\
\hline Broth in $T_{\max }$ & & & $<.0001$ & 0.075 & 98.10 \\
\hline$T_{\max } \mathrm{BHI}$ & 44.51 & 0.266 & $<.0001$ & & \\
\hline$T_{\max } \mathrm{TPB}$ & 41.33 & 1.526 & $<.0001$ & & \\
\hline$T_{\max } \mathrm{TSB}$ & 40.94 & 1.202 & $<.0001$ & & \\
\hline$T_{\max } \mathrm{UND}$ & 42.92 & 0.466 & $<.0001$ & & \\
\hline Broth in $T_{\min }$ & & & $<.0001$ & 3.803 & 3.700 \\
\hline$T_{\min } \mathrm{BHI}$ & -1.390 & 0.377 & $<.0001$ & & \\
\hline$T_{\min } \mathrm{TPB}$ & -0.649 & 0.454 & 0.153 & & \\
\hline$T_{\min } \mathrm{TSB}$ & 0.346 & 0.432 & 0.423 & & \\
\hline$T_{\min } \mathrm{UND}$ & -1.536 & 0.370 & $<.0001$ & & \\
\hline Broth in $T_{\text {opt }}$ & & & $<.0001$ & 0.191 & 95.20 \\
\hline$T_{\text {opt }} \mathrm{BHI}$ & 36.85 & 0.228 & $<.0001$ & & \\
\hline$T_{\text {opt }}$ TPB & 37.94 & 0.706 & $<.0001$ & & \\
\hline$T_{\text {opt }}$ TSB & 37.48 & 0.917 & $<.0001$ & & \\
\hline$T_{\text {opt }} \mathrm{UND}$ & 37.31 & 0.589 & $<.0001$ & & \\
\hline Broth in $\mu_{\mathrm{opt}}$ & & & $<.0001$ & 3.851 & 2.400 \\
\hline$\mu_{\mathrm{opt}} \mathrm{BHI}$ & 0.947 & 0.083 & $<.0001$ & & \\
\hline$\mu_{\mathrm{opt}} \mathrm{TPB}$ & 1.058 & 0.295 & $<.0001$ & & \\
\hline$\mu_{\mathrm{opt}}$ TSB & 0.805 & 0.105 & $<.0001$ & & \\
\hline$\mu_{\mathrm{opt}} \mathrm{UND}$ & 1.032 & 0.075 & $<.0001$ & & \\
\hline Broth in $p H_{\mathrm{opt}}$ & & & $<.0001$ & 3.851 & 2.400 \\
\hline$p H_{\text {opt }} \mathrm{BHI}$ & 6.984 & 0.156 & $<.0001$ & & \\
\hline$p H_{\text {opt }}$ TPB & 7.144 & 0.104 & $<.0001$ & & \\
\hline$p H_{\mathrm{opt}} \mathrm{TSB}$ & 7.653 & 0.160 & $<.0001$ & & \\
\hline$p H_{\mathrm{opt}} \mathrm{UND}$ & 6.993 & 0.097 & $<.0001$ & & \\
\hline Broth in $p H_{\min }$ & & & $<.0001$ & 0.300 & 92.40 \\
\hline$p H_{\min } \mathrm{BHI}$ & 4.471 & 0.019 & $<.0001$ & & \\
\hline$p H_{\min }$ ТPB & 4.194 & 0.064 & $<.0001$ & & \\
\hline$p H_{\min }$ TSB & 4.201 & 0.060 & $<.0001$ & & \\
\hline$p H_{\min } \mathrm{UND}$ & 4.264 & 0.041 & $<.0001$ & & \\
\hline Broth in $p H_{\max }$ & & & $<.0001$ & 0.078 & 98.00 \\
\hline$p H_{\max } \mathrm{BHI}$ & 8.453 & 0.040 & $<.0001$ & & \\
\hline$p H_{\max }$ ТРВ & 8.317 & 1.085 & $<.0001$ & & \\
\hline$p H_{\max }$ TSB & 8.399 & 0.697 & $<.0001$ & & \\
\hline$p H_{\max }$ UND & 9.479 & 0.146 & $<.0001$ & & \\
\hline Reading in $T_{\max }$ & & & $<.0001$ & 3.940 & 0.200 \\
\hline$T_{\max } \mathrm{CFU}$ & 43.81 & 0.328 & $<.0001$ & & \\
\hline$T_{\max } \mathrm{OD}$ & 43.91 & 0.174 & $<.0001$ & & \\
\hline Reading in $T_{\min }$ & & & 0.947 & 3.950 & 0.000 \\
\hline$T_{\min } \mathrm{CFU}$ & -1.159 & 0.242 & $<.0001$ & & \\
\hline$T_{\min } \mathrm{OD}$ & -0.574 & 0.340 & 0.091 & & \\
\hline Reading in $T_{\text {opt }}$ & & & $<.0001$ & 0.255 & 93.50 \\
\hline$T_{\text {opt }} \mathrm{CFU}$ & 38.43 & 0.366 & $<.0001$ & & \\
\hline$T_{\mathrm{opt}} \mathrm{OD}$ & 36.79 & 0.202 & $<.0001$ & & \\
\hline Reading in $\mu_{\mathrm{opt}}$ & & & $<.0001$ & 3.949 & 0.000 \\
\hline$\mu_{\mathrm{opt}} \mathrm{CFU}$ & 0.898 & 0.072 & $<.0001$ & & \\
\hline$\mu_{\mathrm{opt}} \mathrm{OD}$ & 1.401 & 0.087 & $<.0001$ & & \\
\hline Reading in $p H_{\mathrm{opt}}$ & & & $<.0001$ & 3.949 & 0.000 \\
\hline$p H_{\mathrm{opt}} \mathrm{CFU}$ & 5.926 & 0.233 & $<.0001$ & & \\
\hline$p H_{\mathrm{opt}} \mathrm{OD}$ & 6.263 & 0.265 & $<.0001$ & & \\
\hline Reading in $p H_{\min }$ & & & $<.0001$ & 3.753 & 5.000 \\
\hline$p H_{\min } \mathrm{CFU}$ & 4.255 & 0.027 & $<.0001$ & & \\
\hline$p H_{\min } \mathrm{OD}$ & 4.468 & 0.023 & $<.0001$ & & \\
\hline Reading in $p H_{\max }$ & & & 0.002 & 3.950 & 0.000 \\
\hline$p H_{\max } \mathrm{CFU}$ & 9.591 & 0.162 & $<.0001$ & & \\
\hline$p H_{\max }$ OD & 8.365 & 0.385 & $<.0001$ & & \\
\hline
\end{tabular}

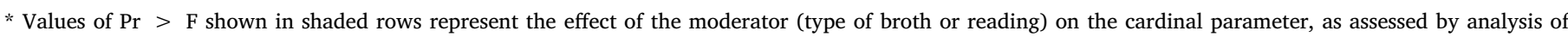
variance. 

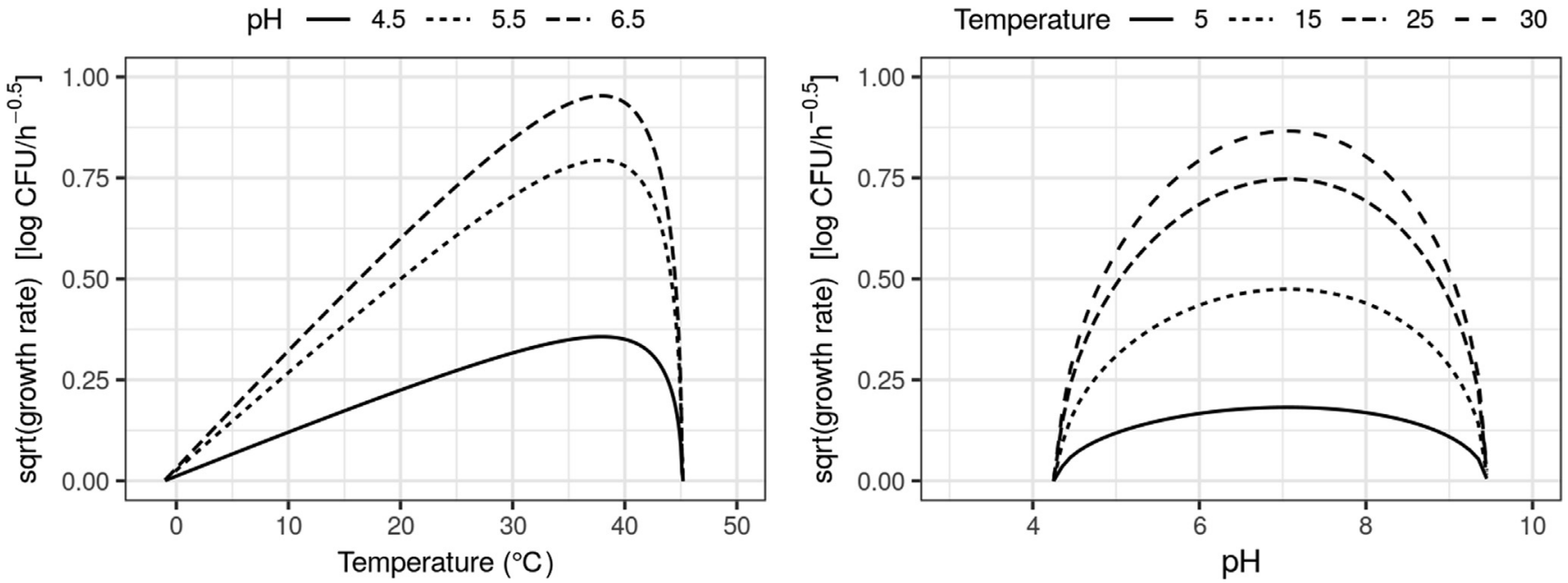

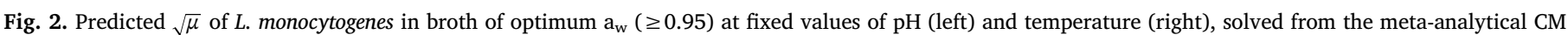
[temperature] $[\mathrm{pH}]$ null model.
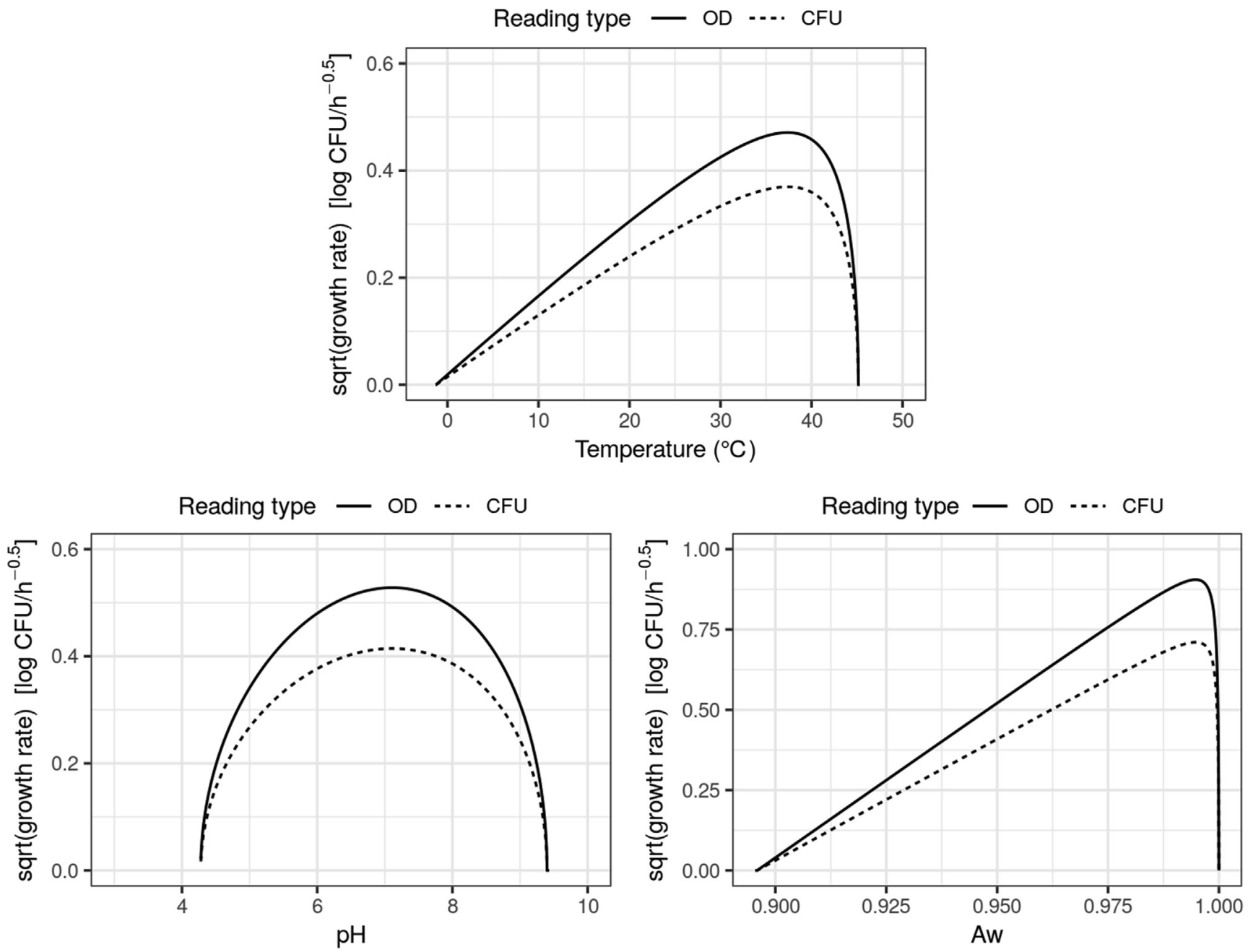

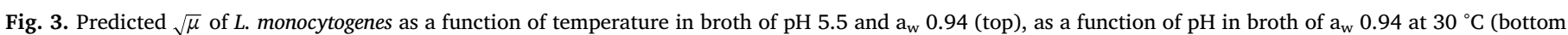

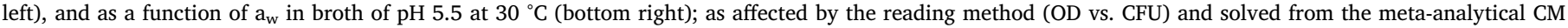
[temperature $][\mathrm{pH}]\left[\mathrm{a}_{\mathrm{w}}\right]$ final model.

$\left(\mathrm{R}^{2}=2.40-98.1 \%\right)$, even more than in the first null model (25-70\%). This was caused by the inclusion of the $\mathrm{pH}$ term, which allowed to absorb some of the variability caused by broths of different $\mathrm{pH}$ values. This means that some variability that was only being attributed to the broth type in the CM[temperature] meta-regression model, was in fact also linked to the distinct $\mathrm{pH}$ values that each medium can present. Different types of media (either general all-purpose media, such as TSB, $\mathrm{BHI}$ and TPB, or selective) may present distinct initial $\mathrm{pH}$ values and 
Table 4

Estimates of the meta-analytical $\mathrm{CM}[$ temperature $][\mathrm{pH}]\left[\mathrm{a}_{\mathrm{w}}\right]$ model predicting the square root of the maximum growth rate $[\log \mathrm{CFU} / \mathrm{h}]$ of $L$. monocytogenes in broth $(N=2009)$. Heterogeneity analysis of the final model comprises between-study variance $\left(\tau^{2}\right)$, intra-class correlation $\left(\mathrm{I}^{2}\right)$, residual between-study variance $\left(\tau_{\text {res }}^{2}\right)$ and explained between-study variance $\left(R^{2}\right)$.

\begin{tabular}{|c|c|c|c|c|}
\hline Final model & Mean & Standard error & $\operatorname{Pr}>|t|$ & Heterogeneity \\
\hline \multicolumn{5}{|l|}{ Fixed effects } \\
\hline \multicolumn{5}{|l|}{$\mu_{\mathrm{opt}}$} \\
\hline $\mathrm{CFU}$ & 0.947 & 0.085 & $<0.0001$ & \\
\hline $\mathrm{OD}$ & 1.289 & 0.092 & $<0.0001$ & \\
\hline$T_{\min }$ & -1.273 & 0.179 & $<0.0001$ & \\
\hline$T_{\max }$ & 45.12 & 0.013 & $<0.0001$ & \\
\hline$T_{\mathrm{opt}}$ & 37.26 & 0.688 & $<0.0001$ & \\
\hline$p H_{\min }$ & 4.303 & 0.014 & $<0.0001$ & Null model: \\
\hline$p H_{\max }$ & 9.483 & 0.111 & $<0.0001$ & $\tau^{2}=13.60$ \\
\hline $\mathrm{pH}_{\mathrm{opt}}$ & 7.085 & 0.080 & $<0.0001$ & $\mathrm{I}^{2}=94.4 \%$ \\
\hline$a_{w \min }$ & 0.894 & 0.002 & $<0.0001$ & \\
\hline$a_{w \text { opt }}$ & 0.995 & 0.001 & $<0.0001$ & \\
\hline \multicolumn{5}{|c|}{ Nested random effects } \\
\hline \multicolumn{5}{|l|}{ Broth $\mathrm{m}$} \\
\hline $\mathrm{s}_{\mathrm{u} \mathrm{m}}\left(\mu_{\mathrm{opt}}\right)$ & 0.093 & & & $\tau_{\mathrm{res}}^{2}=11.49$ \\
\hline $\mathrm{s}_{\mathrm{v} \mathrm{m}}\left(T_{\mathrm{opt}}\right)$ & 0.026 & & & $\mathrm{R}^{2}=15.5 \%$ \\
\hline $\mathrm{s}_{\mathrm{w} \mathrm{m}}\left(p H_{\text {opt }}\right)$ & 0.001 & & & \\
\hline $\mathrm{s}_{\mathrm{z} \mathrm{m}}\left(a_{w}\right.$ opt $)$ & 0.001 & & & \\
\hline \multicolumn{5}{|c|}{ Study $\mathrm{j}$ in Broth $\mathrm{m}$} \\
\hline$s_{\mathrm{u} \mathrm{m}(\mathrm{j})}\left(\mu_{\mathrm{opt}}\right)$ & 0.409 & & & \\
\hline $\mathrm{s}_{\mathrm{v} \mathrm{m}(\mathrm{j})}\left(T_{\mathrm{opt}}\right)$ & 3.369 & & & \\
\hline $\mathrm{s}_{\mathrm{w} \mathrm{m}(\mathrm{j})}\left(p H_{\mathrm{opt}}\right)$ & 0.161 & & & \\
\hline $\mathrm{s}_{\mathrm{z} \mathbf{m}(\mathrm{j})}\left(a_{w}\right.$ opt $)$ & 0.002 & & & \\
\hline s (residual) & 0.061 & & & \\
\hline
\end{tabular}

buffering capacities. Moreover, the evolution of the $\mathrm{pH}$ has also shown to be dependent on the carbon source used (Sánchez-Clemente, Igeño, Población, Guijo, Merchán, \& Blasco, 2018), which may vary depending on the selected medium. These factors may be able to cause changes in extracellular $\mathrm{pH}$, and thus are likely to influence bacterial cell growth (Sánchez-Clemente, Igeño, Población, Guijo, Merchán, \& Blasco, 2018). In this sense, further investigation on the effect of different types of media in $L$. monocytogenes growth and enumeration should be undertaken. Nevertheless, bacterial physiology (such as nutritional type, bacterial metabolism, bacterial viability, etc.) may also affect growth and should not be dismissed (Barer, 2012).

Regarding the influence of the reading method on the parameters, the inclusion of the $\mathrm{pH}$ term caused a considerable increase of the explained between-study variability in $T_{\text {opt }}\left(\mathrm{R}^{2}=93.5 \%\right)$, while reducing the $\mathrm{R}^{2}$ of other models with moderators estimating different parameters. This means that the reading method influences $T_{\text {opt }}$ estimation the most, leading to greater variability, in comparison to other cardinal values for temperature $\left(T_{\max }, T_{\min }\right.$ and $\left.\mu_{\mathrm{opt}}\right)$ and $\mathrm{pH}\left(\mathrm{pH} H_{\max }, p H_{\min }\right.$ and $\mathrm{pH}_{\mathrm{opt}}$ ).

The results of the null model in Table 3 were used to produce the graphs presented in Fig. 2, that show the predicted square-roots of $L$. monocytogenes growth rates in broth of optimum $\mathrm{a}_{\mathrm{w}}(\geq 0.95)$ at fixed values of $\mathrm{pH}$ and temperature. The aim of this figure is to demonstrate the great impact of sub-optimal conditions of $\mathrm{pH}$ and temperature on the optimum growth rate, which decreases as the conditions move further away from the optimum. Additional simulations for the optimal $\mathrm{pH}$ range selected $(6.5 \leq \mathrm{pH} \leq 8)$ are available in the Supplementary File 2 (Fig. S2) and demonstrate the reduced impact of $\mathrm{pH}$ values within the optimum range selected on the optimum growth rate.

\subsection{Final CM[temperature $][\mathrm{pH}]\left[a_{w}\right]$ meta-regression model}

After evaluating the outcomes of the previous models, it became clear that the type of broth, having a strong influence on the cardinal parameters, was able to explain a substantial proportion of the total between-study variability. With this in mind, type of broth was included in the final $\mathrm{CM}$ [temperature $][\mathrm{pH}]\left[\mathrm{a}_{\mathrm{w}}\right]$ meta-regression model in a random-effects structure of primary studies nested within type of broth.

On the other hand, even though the reading method has some effect on the cardinal parameters, as shown by the results of the CM[temperature] and $\mathrm{CM}$ [temperature][pH] models (see Table 2 and 3, respectively), in the final model, this moderator was only introduced as a predictor of $\mu_{\mathrm{opt}}$, since no enhancement in goodness of fit was achieved if reading method was introduced to other cardinal parameters. Nonetheless, this moderator was indeed essential as a predictor of $\mu_{\mathrm{opt}}$ to absorb the variability caused by the two distinct reading methods. Thus, the optimum growth rate $\mu_{\mathrm{opt}}$ of $L$. monocytogenes was found to be lower when measured as CFU $(0.967 \log \mathrm{CFU} / \mathrm{h}$; $\mathrm{SE}=0.094 \log \mathrm{CFU} /$ h) than when measured as OD $(1.324 \log \mathrm{CFU} / \mathrm{h}$; $\mathrm{SE}=0.101 \log \mathrm{CFU} /$ h). The influence of the distinct reading methods on $\mu_{\mathrm{opt}}$ can be seen in Fig. 3.

The cardinal parameters, applicable to both reading types, were: $T_{\min }=-1.273{ }^{\circ} \mathrm{C}\left(\mathrm{SE}=0.179{ }^{\circ} \mathrm{C}\right), T_{\text {opt }}=37.26{ }^{\circ} \mathrm{C}\left(\mathrm{SE}=0.688{ }^{\circ} \mathrm{C}\right)$, $T_{\max }=45.12{ }^{\circ} \mathrm{C}\left(\mathrm{SE}=0.013{ }^{\circ} \mathrm{C}\right), p H_{\min }=4.303(\mathrm{SE}=0.014)$, $p H_{\text {opt }}=7.085(\mathrm{SE}=0.080), p H_{\max }=9.483(\mathrm{SE}=0.111), a_{w}$ $\min =0.894(\mathrm{SE}=0.002)$ and $a_{w \text { opt }}=0.995(\mathrm{SE}=0.001)($ Table 4$)$. The aforementioned cardinal parameters can be considered as pooled cardinal parameters since they represent the synthesis of 2009 microbial growth experiments.

Adjusting the $\mathrm{CM}[$ temperature $][\mathrm{pH}]\left[\mathrm{a}_{\mathrm{w}}\right]$ null model to the full data set $(\mathrm{N}=2009)$ produced a meta-analytical model of high intra-class variability $\left(\mathrm{I}^{2}=94.4 \%\right)$. Nevertheless, the introduction of reading method as a moderator of $\mu_{\text {opt }}$ explained $15.5 \%$ of such between-study variability (Table 4 and Fig. 3). The $s$ values for broth and for study in broth shown in Table 4 correspond to the standard deviations of the nested random effects placed on $\mu_{\mathrm{opt}}, T_{\mathrm{opt}}, p H_{\mathrm{opt}}$ and $a_{w \text { opt }}$. With higher values of $s_{\mathrm{u} \mathrm{m}}\left(\mu_{\mathrm{opt}}\right)$ and $\mathrm{s}_{\mathrm{v} \mathrm{m}}\left(T_{\mathrm{opt}}\right)$, as well as $\mathrm{s}_{\mathrm{u} \text { m(j) }}\left(\mu_{\mathrm{opt}}\right)$ and $\mathrm{s}_{\mathrm{v} \mathrm{m}(\mathrm{j})}$ $\left(T_{\text {opt }}\right)$, this model shows that the type of broth produced more variability in the estimates of $\mu_{\mathrm{opt}}$ and $T_{\mathrm{opt}}$ than in $p H_{\mathrm{opt}}$ and $a_{w \text { opt }}$. However, since $\mathrm{s}_{\mathrm{v} \text { m(j) }}\left(T_{\mathrm{opt}}\right)$ is considerably superior than $\mathrm{s}_{\mathrm{v} m}\left(T_{\mathrm{opt}}\right)$, it is clear that the different studies introduced greater variability into $T_{\mathrm{opt}}$ than the medium type per se ( 3.369 vs. 0.026 , respectively).

To demonstrate the usefulness of the multilevel final model in the estimation of $\mu_{\max }, \mathrm{a}_{\mathrm{w}}$ or $\mathrm{pH}$, Figs. 4 and 5 were constructed. The graphs from these figures show the predicted $\sqrt{\mu}$ of L. monocytogenes, solved from the $\mathrm{CM}[$ temperature $][\mathrm{pH}]\left[\mathrm{a}_{\mathrm{w}}\right]$ meta-regression model, as a function of temperature (Fig. 4) and water activity (Fig. 5) in broth of different $\mathrm{pH}$ values $(4.5,5.5,6.5)$ and at different water activities or temperatures, respectively, as measured by the $\mathrm{CFU}$ reading method. Additional simulations of the $\mathrm{CM}[$ temperature $][\mathrm{pH}]\left[\mathrm{a}_{\mathrm{w}}\right]$ meta-regression model considering optimal $\mathrm{pH}$ values $(7,7.5,8)$ are available in the Supplementary File 2 (Figs. S3 and S4). These simulations show the predicted $\sqrt{\mu}$ of L. monocytogenes as a function of temperature (Fig. S3) and water activity (Fig. S4) in broth of different $\mathrm{pH}$ values and at different water activities or temperatures, respectively, as measured by the $\mathrm{CFU}$ reading method. Fig. $\mathrm{S} 3$ shows that, in the optimum range of $\mathrm{pH}$ (>6.5), differences in $a_{w}$ (also in the "optimum" range, from 0.95 onwards) cause considerable variation in the optimum growth rate. On the other hand, in the optimum range of $\mathrm{a}_{\mathrm{w}}(>0.95)$, differences in $\mathrm{pH}$ (also in the "optimum" range, from 6.5 onwards) cause less variability in the optimum growth rate, as shown by Fig. S4 (note that $\mu_{\max }$ corresponding to each of the three $\mathrm{pH}$ values are similar at a given temperature). The final model has been made available online to perform simulations of L. monocytogenes growth: https://vcadavez.shinyapps.io/ ListeriaCardinalModel.

In order to evaluate the quality of the $\mathrm{CM}[$ temperature $][\mathrm{pH}]\left[\mathrm{a}_{\mathrm{w}}\right]$ meta-regression, the histogram of Pearson's residuals was built, and the goodness-of-fit was assessed, as shown in Fig. 6. Since the residuals are symmetrically distributed around zero in the histogram, and the R of the goodness-of-fit is particularly high for a meta-analysis study $(\mathrm{R}=0.974)$, it can be stated that the model is robust, and that the 

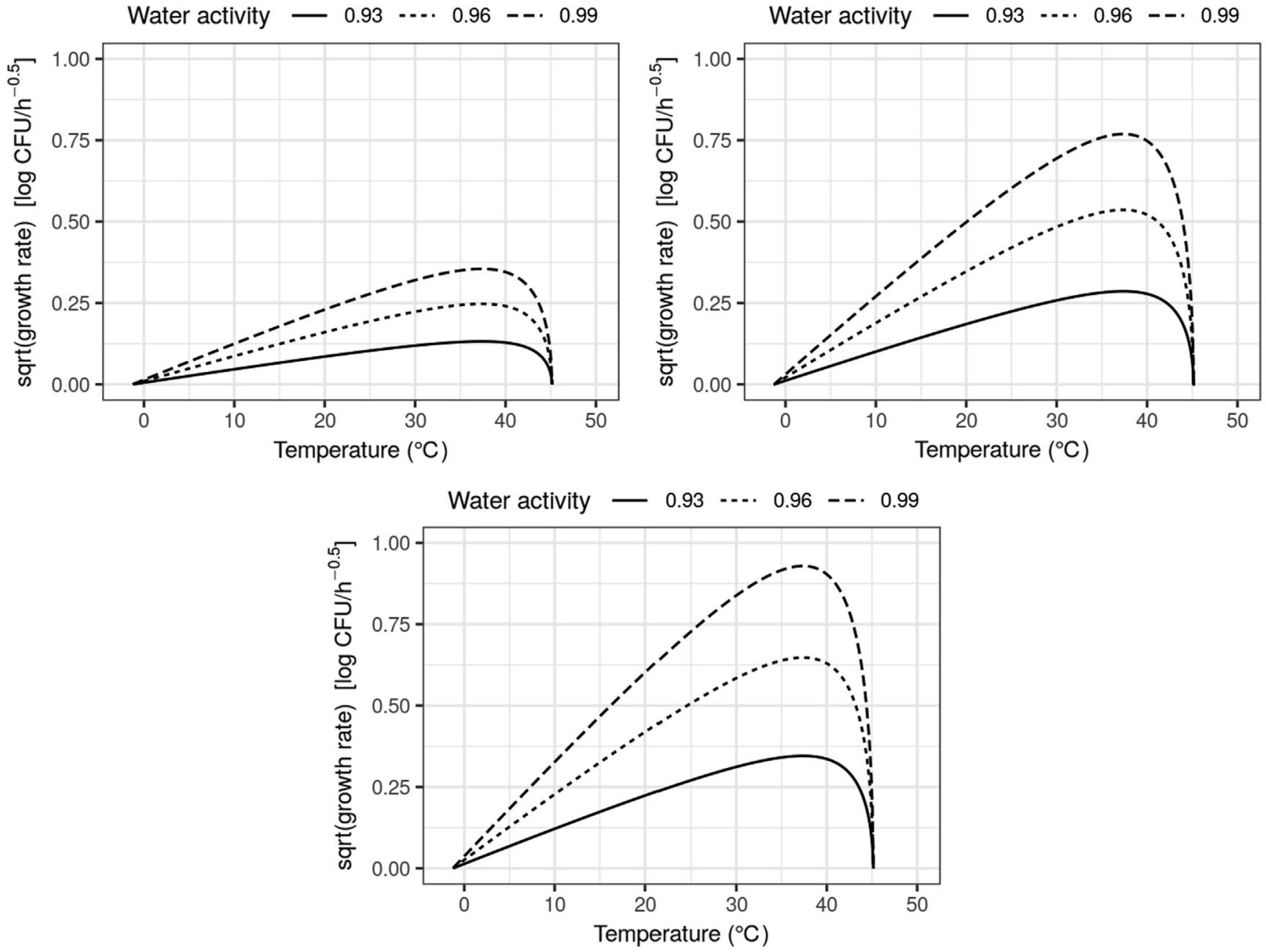

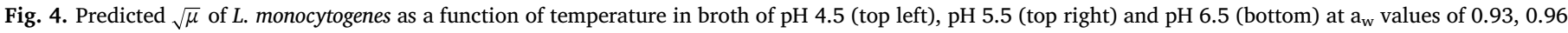
and 0.99 as measured by the CFU reading method, solved from the meta-analytical CM[temperature] $[\mathrm{pH}]\left[\mathrm{a}_{\mathrm{w}}\right]$ final model.

estimates produced by this final model are accurate and comprehensive values that may be used as reference when using cardinal parameter models. These results also validate the value of meta-analysis metaregression models in estimating cardinal parameters.

The models were also assessed in terms of any possible randomeffects correlation by estimating the terms of the covariance matrix from the null models (not shown). In the first model, CM[temperature], no significant correlation was found between any parameters, with the exception of the shifts in $T_{\text {opt }}$ and $\mu_{\text {opt }}(\mathrm{R}=0.492)$, which was expected and can be explained by the high variability of $\mu$ at distinct temperatures. In the second meta-regression model, $\mathrm{CM}[$ temperature][pH], no correlation was found between the random shifts in the cardinal parameters; only the random effects of $T_{\mathrm{opt}}$ and $\mu_{\mathrm{opt}}$ showed some association $(\mathrm{R}=0.458)$, unlike $p H_{\mathrm{opt}}$ and $\mu_{\mathrm{opt}}(\mathrm{R}=0.110)$, which once again demonstrated the anticipated high variability of $\mu$ caused by temperature, in comparison to $\mathrm{pH}$. Lastly, in the final model, CM[temperature] $[\mathrm{pH}]\left[\mathrm{a}_{\mathrm{w}}\right]$, the random-effects correlations between $\mu_{\mathrm{opt}}$ and $T_{\mathrm{opt}} p H_{\mathrm{opt}}$ and $a_{w}$ opt were $\mathrm{R}=0.867,0.285$ and -0.357 , respectively. All these values support the previous statements made for the first and second models; that shifts in $\mu_{\mathrm{opt}}$ due to primary study are correlated with shifts in $T_{\text {opt }}$. Furthermore, the correlation coefficient, which was positive in all cases, suggests that in a cardinal model, when $T_{\text {opt }}$ is estimated at a higher value, $\mu_{\mathrm{opt}}$ also tends to be estimated at a higher value, and vice versa. Although in the three models, study-specific deviations in $\mu_{\mathrm{opt}}$ were found to be positively associated with study-specific deviations in $T_{\text {opt }}$, a correlated random-effects solution was not opted for in the final model because it did not further improve the fitting quality of the uncorrelated random-effects meta-regression.

To benchmark our findings with the literature, a list of references regarding $L$. monocytogenes cardinal values was examined and the information was summarised in Table 5 . From such table, it is possible to observe variability in the reported values. Among other causes, this may be the result of different authors using distinct strains in their experiments, reason why integrating strain variability into predictive models is crucial to achieve more accurate predictions, as emphasized by Aryani, den Besten, Hazeleger, and Zwietering (2015). In our study, the inclusion of strain as a moderator was not possible due to uneven distribution of the data, as referred before. Overall, the estimates obtained from the developed $\mathrm{CM}[$ temperature $][\mathrm{pH}]\left[\mathrm{a}_{\mathrm{w}}\right]$ meta-regression model are in agreement with those from literature, considering the variability. Furthermore, they are within the range of variation of the cardinal values for temperature and $\mathrm{pH}$ referenced by Ellouze et al. (2010); $a_{w \text { min }}$ was the only parameter whose estimated value did not fit within the referenced range. Nonetheless, all the estimates from our model, including that for $a_{w \mathrm{~min}}$, are aligned with the distributions described by Couvert et al. (2010).

The dispersion of the values reported in literature (in particular, for temperature) and the reduced amount of information for some factors ( $\mathrm{pH}$ and $\mathrm{a}_{\mathrm{w}}$ ) support the novelty and usefulness of our meta-regression model and its estimated cardinal parameters to be used as reference values in quantitative risk assessment studies. 

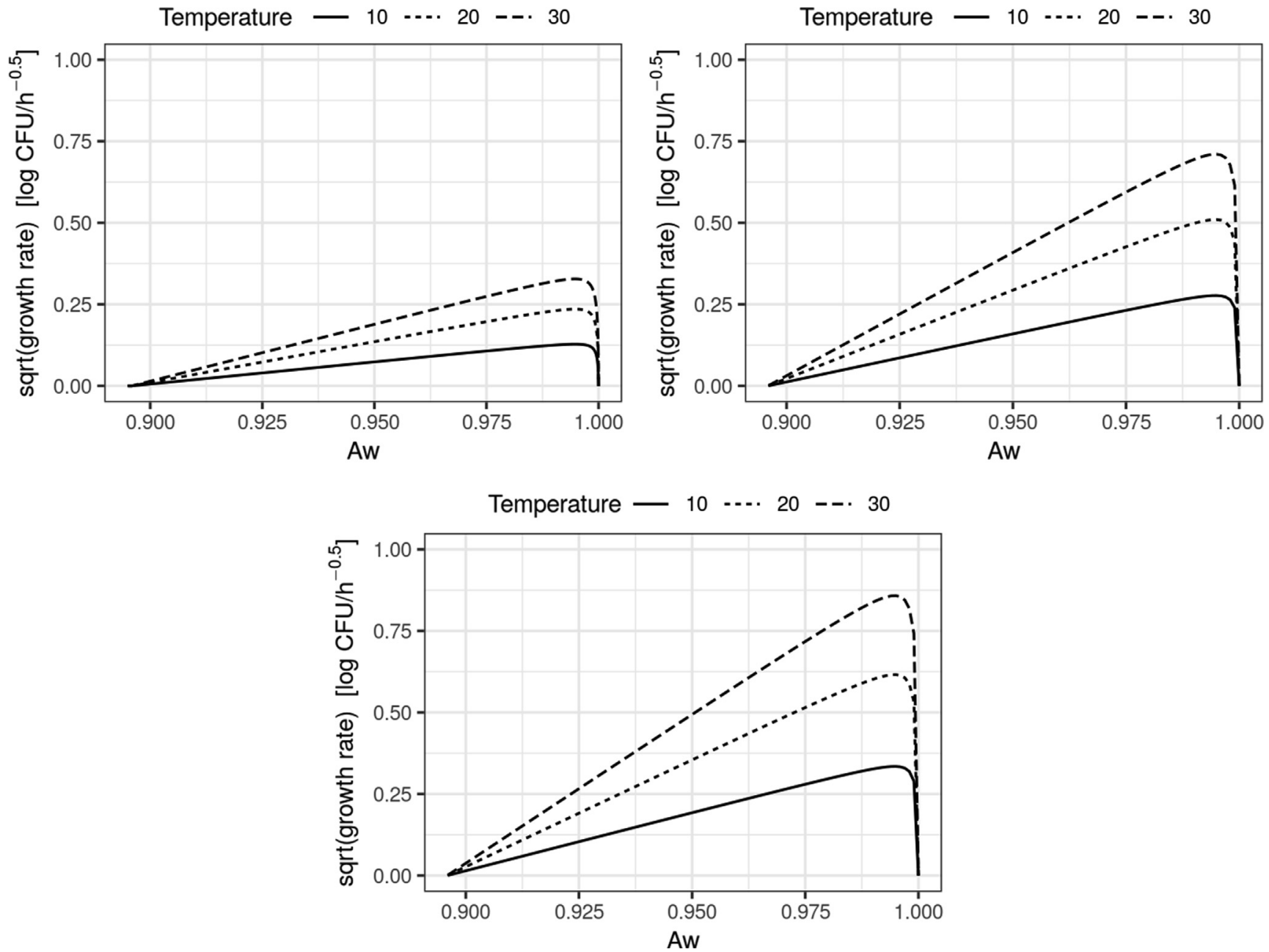

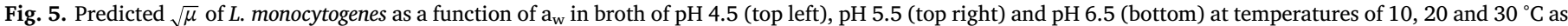
measured by the CFU reading method, solved from the meta-analytical $\mathrm{CM}\left[\right.$ temperature] $[\mathrm{pH}]\left[\mathrm{a}_{\mathrm{w}}\right]$ final model.
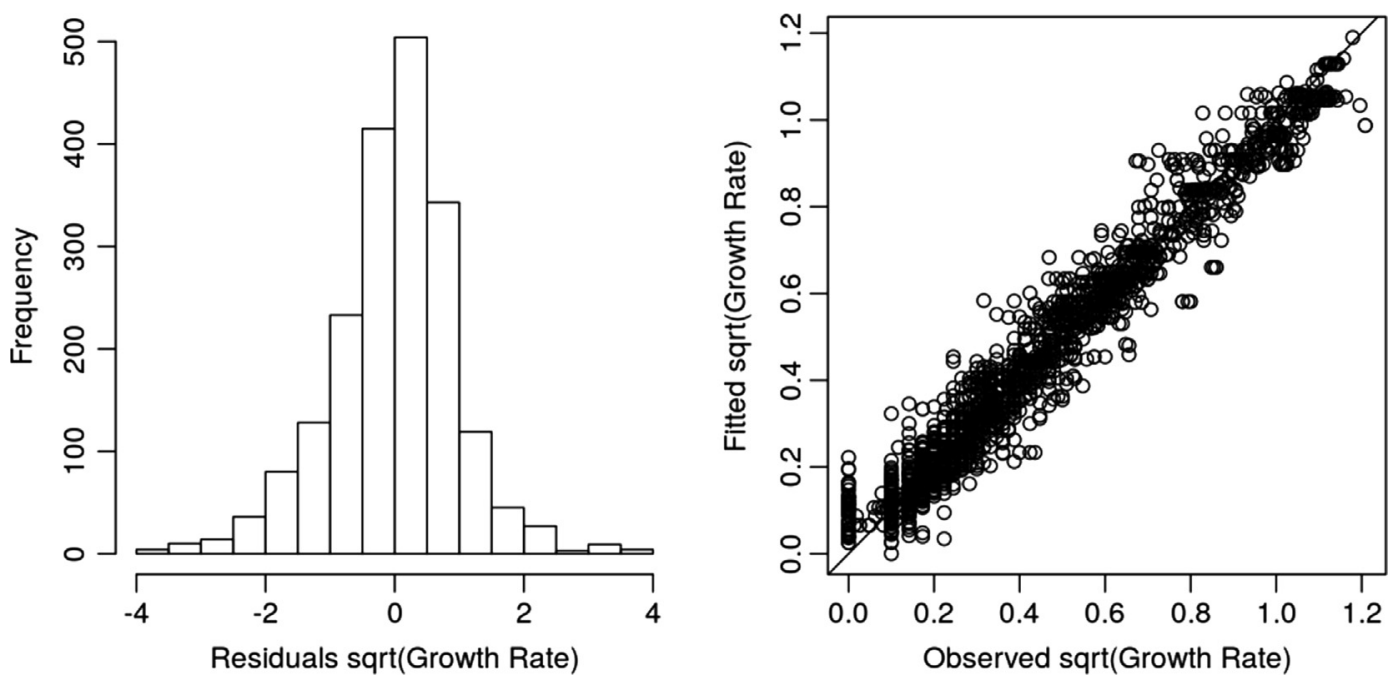

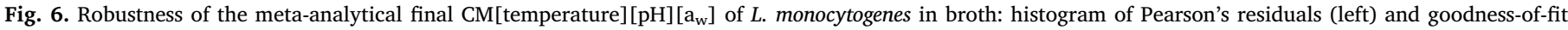
(right).

\section{Conclusions}

This study shows that the assessment of cardinal values using published growth experiments is possible, and valuable to provide an insight into the sources of variability. With this study, it was possible to observe the strong influence that the type of broth chosen for growing L. monocytogenes can exert on the kinetic parameters extracted by the cardinal parameter model. Reading method has also an important 
Table 5

Estimated distributions, ranges, and values of cardinal parameters for growth of $L$. monocytogenes from literature.

\begin{tabular}{|c|c|c|c|c|}
\hline Factor & $X_{\min }$ & $X_{\mathrm{opt}}$ & $X_{\max }$ & Reference \\
\hline \multirow[t]{10}{*}{$\mathrm{T}\left({ }^{\circ} \mathrm{C}\right)$} & -3.00 & 35.0 & 43.0 & (Bajard, Rosso, Fardel, \& Flandrois, 1996) \\
\hline & -2.70 & 38.7 & 42.3 & (Augustin \& Carlier, 2000b) \\
\hline & -0.70 & 39.0 & 39.7 & (Augustin \& Carlier, 2000b) \\
\hline & 0.50 & 39.7 & 47.7 & (Augustin \& Carlier, 2000b) \\
\hline & -1.72 & 37.0 & 45.5 & (Augustin, Zuliani, Cornu, \& Guillier, 2005) \\
\hline & -1.70 & 38.1 & 45.1 & (Membré et al., 2005) \\
\hline & - & 38.0 & 42.5 & (Ellouze, Gauchi, \& Augustin, 2010) \\
\hline & 1.16 & 35.9 & 46.4 & Nyhan, Begley, Mutel, Qu, Johnson, and Callanan (2018) \\
\hline & -2.8 to 0.6 & 36.4 to 40 & 40.5 to 46.1 & (Ellouze, Gauchi, \& Augustin, 2010) \\
\hline & $\mathrm{N}(-1.08,0.72)$ & $\mathrm{N}(38.2,0.76)$ & $\mathrm{N}(43.3,1.20)$ & Couvert et al., 2010* \\
\hline \multirow[t]{3}{*}{$\mathrm{pH}$} & 4.20 & - & - & (Ellouze, Gauchi, \& Augustin, 2010) \\
\hline & 3.90 to 4.50 & - & - & (Ellouze, Gauchi, \& Augustin, 2010) \\
\hline & $\mathrm{N}(4.19,0.12)$ & 7.0 & - & (Couvert et al., 2010)* \\
\hline \multirow[t]{2}{*}{$a_{w}$} & 0.901 to 0.943 & - & - & (Ellouze, Gauchi, \& Augustin, 2010) \\
\hline & $\mathrm{N}(0.922,0.009)$ & 0.997 & - & Couvert et al., 2010* \\
\hline
\end{tabular}

* The distributions in Couvert et al. (2010) were provided by Sym'Previus (http://symprevius.eu/en/).

effect, but mainly on the optimum growth rate. Referring to the inoculum concentration as moderator, no conclusions could be drawn as this variable was highly confounded with the reading method. This study also revealed the challenge to estimate cardinal values when few data is available. To increase the precision of experimentally estimated cardinal values, the authors advise to perform a high number of experiments (especially close to the growth boundaries), as their estimation is more challenging than the estimation of parameters at optimum conditions.

By integrating the outcomes from numerous $L$. monocytogenes growth experiments gathered from 49 sources, the cardinal parameters for temperature, $\mathrm{pH}$ and $\mathrm{a}_{\mathrm{w}}$ were obtained through a meta-regression approach. As such, these cardinal parameters are accurate estimates that can be used as reference values in process risk models and/or risk assessments. Nonetheless, as the model built uses data from experiments in broth, predictions in liquid and solid foods will require validation.

\section{CRediT authorship contribution statement}

Beatriz Nunes Silva: Data curation, Formal analysis, Investigation, Writing - original draft, Validation. Vasco Cadavez: Conceptualization, Data curation, Formal analysis, Funding acquisition, Investigation, Methodology, Project administration, Writing - review \& editing, Software, Resources, Supervision. José António Teixeira: Project administration, Supervision. Mariem Ellouze: Conceptualization, Data curation, Funding acquisition, Investigation, Project administration, Writing - review \& editing, Visualization, Resources, Supervision. Ursula Gonzales-Barron: Conceptualization, Data curation, Formal analysis, Funding acquisition, Investigation, Methodology, Project administration, Writing - review \& editing, Software, Resources, Supervision.

\section{Acknowledgments}

U. Gonzales-Barron and V. Cadavez are grateful to the Foundation for Food Science and Technology (FCT, Portugal) for financial support through national funds FCT/MCTES to CIMO (UIDB/00690/2020). U. Gonzales-Barron acknowledges the national funding by FCT, P.I., through the Institutional Scientific Employment Program contract.

\section{Appendix A. Supplementary data}

Supplementary data to this article can be found online at https:// doi.org/10.1016/j.foodres.2020.109476.

\section{References}

Aryani, D. C., den Besten, H. M. W., Hazeleger, W. C., \& Zwietering, M. H. (2015). Quantifying strain variability in modeling growth of Listeria monocytogenes. International Journal of Food Microbiology, 208, 19-29. https://doi.org/10.1016/j. ijfoodmicro.2015.05.006.

Augustin, J. C., \& Carlier, V. (2000a). Modelling the growth rate of Listeria monocytogenes with a multiplicative type model including interactions between environmental factors. International Journal of Food Microbiology, 56, 53-70. https://doi.org/10.1016/ S0168-1605(00)00224-5.

Augustin, J. C., \& Carlier, V. (2000b). Mathematical modelling of the growth rate and lag time for Listeria monocytogenes. International Journal of Food Microbiology, 56, 29-51. https://doi.org/10.1016/s0168-1605(00)00223-3.

Augustin, J. C., Zuliani, V., Cornu, M., \& Guillier, L. (2005). Growth rate and growth probability of Listeria monocytogenes in dairy, meat and seafood products in suboptimal conditions. Journal of Applied Microbiology, 99, 1019-1042. https://doi.org/ 10.1111/j.1365-2672.2005.02710.x.

Bajard, S., Rosso, L., Fardel, G., \& Flandrois, J. P. (1996). The particular behaviour of Listeria monocytogenes under sub-optimal conditions. Food Microbiology, 29, 201-211. https://doi.org/10.1016/0168-1605(95)00031-3.

Baka, M., Van Derlinden, E., Boon, K., Mertens, L., \& Van Impe, J. F. (2013). Impact of pH on the cardinal temperatures of $E$. coli K12: Evaluation of the gamma hypothesis. Food Control, 29(2), 328-335. https://doi.org/10.1016/j.foodcont.2012.04.022.

Baranyi, J., \& Roberts, T. A. (1994). A dynamic approach to predicting bacterial growth in food. International Journal of Food Microbiology, 23, 277-294. https://doi.org/10. 1016/0168-1605(94)90157-0.

Barer, M. R. (2012). Bacterial growth, physiology, and death. In D. Greenwood, M. Barer, R. Slack, \& W. Irving (Eds.). Medical Microbiology, A guide to Microbial Infections: Pathogenesis, Immunity, Laboratory Investigation, and Control (pp. 39-53). (18th ed.). Elsevier. https://doi.org/10.1016/B978-0-7020-4089-4.00019-6.

Borenstein, M., Hedges, L. V., Higgins, J. P. T., \& Rothstein, H. R. (2009). Introduction to Meta-Analysis. Chichester, UK: John Wiley \& Sons Ltd.

Commission Regulation (EC) No. 2073/2005 of 15 November 2005 on microbiological criteria for foodstuffs. https://www.fsai.ie/uploadedFiles/Consol_Reg2073_2005.pdf.

Couvert, O., Pinon, A., Bergis, H., Bourdichon, F., Carlin, F., Cornu, M., ... Augustin, J. C. (2010). Validation of a stochastic modelling approach for Listeria monocytogenes growth in refrigerated foods. International Journal of Food Microbiology, 144(2), 236-242. https://doi.org/10.1016/j.ijfoodmicro.2010.09.024.

EFSA BIOHAZ Panel (2018). Scientific Opinion on the Listeria monocytogenes contamination of ready-to-eat foods and the risk for human health in the EU. EFSA Panel on Biological Hazards. EFSA Journal, 16(1), https://doi.org/10.2903/j.efsa.2018. 5134.

European Food Safety Authority (EFSA); European Centre for Disease Prevention and Control (ECDC) (2018). The European Union summary report on trends and sources of zoonoses, zoonotic agents and food-borne outbreaks in 2017. EFSA Journal 16, 67-68.

European Food Safety Authority (EFSA); European Centre for Disease Prevention (ECDC) (2019). The European Union One Health 2018 Zoonoses Report. EFSA Journal 17, 73-79.

Ellouze, M., Gauchi, J. P., \& Augustin, J. C. (2010). Global sensitivity analysis applied to a contamination assessment model of Listeria monocytogenes in cold smoked salmon at consumption. Risk Analysis, 30(5), 841-852. https://doi.org/10.1111/j.1539-6924. 2010.01380.x.

Gnanou Besse, N., Audinet, N., Barre, L., Cauquil, A., Cornu, M., \& Colin, P. (2006). Effect of the inoculum size on Listeria monocytogenes growth in structured media. International Journal of Food Microbiology, 110, 43-51. https://doi.org/10.1016/j. ijfoodmicro.2006.03.002.

Gonzales-Barron, U., \& Butler, F. (2011). The use of meta-analytical tools in risk 
assessment for food safety. Food Microbiology, 28, 823-827. https://doi.org/10.1016/ j.fm.2010.04.007.

Lambert, R. J. W., \& Bidlas, E. (2007). A study of the Gamma hypothesis: Predictive modelling of the growth and inhibition of Enterobacter sakazakii. International Journal of Food Microbiology, 115(2), 204-213. https://doi.org/10.1016/j.ijfoodmicro.2006. 10.024 .

McKellar, R. C., \& Lu, X. (2004). Modeling microbial responses in foods. Boca Raton, FL: CRC Press.

Membré, J. M., Leporq, B., Vialette, M., Mettler, E., Perrier, L., Thuault, D., \& Zwietering, M. H. (2005). Temperature effect on bacterial growth rate: quantitative microbiology approach including cardinal values and variability estimates to perform growth simulations on/in food. International Jornal of Food Microbiology, 100, 179-186. https://doi.org/10.1016/j.ijfoodmicro.2004.10.015.

Nyhan, L., Begley, M., Mutel, A., Qu, Y., Johnson, N., \& Callanan, M. (2018). Predicting the combinatorial effects of water activity, $\mathrm{pH}$ and organic acids on Listeria growth in media and complex food matrices. Food Microbiology, 74, 75-85. https://doi.org/10. 1016/j.fm.2018.03.002

Pinheiro, J., Bates, D., DebRoy, S., Sarkar, D., R Core Team (2019). nlme: Linear and Nonlinear Mixed Effects Models. R package version 3.1-142. https://CRAN.R-project. org $/$ package $=$ nlme.

R Core Team (2019). R: A Language and environment for statistical computing. R Foundation for Statistical Computing, Vienna, Austria. http://www.r-project.org/.

Rosso, L., Lobry, J. R., Bajard, S., \& Flandrois, J. P. (1995). Convenient model to describe the combined effects of temperature and $\mathrm{pH}$ on microbial growth. Applied and Environment Microbiology, 61(2), 610-616.

Sánchez-Clemente, R., Igeño, M. I., Población, A. G., Guijo, M. I., Merchán, F., \& Blasco, R. (2018). Study of pH changes in media during bacterial growth of several environmental strains. Proceeding, 2, 1297.

Schlech, W. F., III, \& Acheson, D. (2000). Foodborne listeriosis. Clinical Infectious Diseases, 31(3), 770-775. https://doi.org/10.1086/314008.

Xavier, C., Gonzales-Barron, U., Paula, V., Estevinho, L., \& Cadavez, V. (2014). Metaanalysis of the incidence of foodborne pathogens in Portuguese meats and their products. Food Research International, 55, 311-323. https://doi.org/10.1016/j. foodres.2013.11.024.

Zwietering, M. H., Wijtzes, T., De Wit, J. C., \& Riet, K. V. (1992). A decision support system for prediction of the microbial spoilage in foods. Journal of Food Protection, 55(12), 973-979. https://doi.org/10.4315/0362-028X-55.12.973. 